\author{
I. Г. Ліберг ${ }^{1}$, О. О. Можаєв ${ }^{2}$ Г. А. Кучук ${ }^{1}$ \\ ${ }^{1}$ Національний технічний університет «Харківський Політехнічний Інститут», Харків, Україна \\ ${ }^{2}$ Харківський національний університет внутрішніх справ, Харків, Україна
}

\title{
КОРОТКОСТРОКОВЕ ПРОГНОЗУВАННЯ ТРАФІКА ПРИ СТАТИСТИЧНОМУ МУЛЬТИПЛЕКСУ ВАННІ
}

\begin{abstract}
Анотація. Мета статті - розробка методу, який дозволяє отримати оперативну оцінку основних статистичних характеристик агрегованого трафіка на комутаційному вузлі мультисервісної мережі, що здійснює статистичне мультиплексування вхідних потоків, використовуючи значення відліків вхідних потоків. Результати. Запропоновано метод, що дозволяє отримати оперативну оцінку основних статистичних характеристик (на прикладі математичного сподівання і дисперсії) агрегованого трафіку на комутаційному вузлі мультисервісної мережі, що здійснює статистичне мультиплексування вхідних потоків. Запропонований метод грунтується на апроксимації функції щільності розподілу швидкості окремого вхідного потоку трафіку. Доведено, що для отримання оцінки досить значень максимальної бітової швидкості і берстності кожного вхідного потоку, які розраховуються за відліком трафіку. Точність і часові витрати на розрахунок оцінки визначаються масштабом шкали відліків комутаційного вузла. Великомасштабні шкали підвищують оперативність розрахунку значень статистичних характеристик, однак дають істотну погрішність оцінки, дрібномасштабні шкали збільшують витрати обчислювального ресурсу комутаційного вузла, однак, знижують помилку репрезентативності.
\end{abstract}

Ключов і слов а: агрегований трафік, мультисервисная мережу, комутаційний вузол, берстність, функція щільності розподілу, бітова швидкість потоку..

\section{Вступ}

В даний час повсюдно швидкими темпами розвиваються нові інформаційні та телекомунікаційні технології, спрямовані на підвищення пропускної спроможності існуючих мереж передачі даних. Успіхи в області засобів обчислювальної техніки, використання передавальних середовищ 3 високими швидкостями передачі і малими значеннями ймовірності помилки, різке збільшення обсягів переданого трафіка привели до створення локальних інформаційно-керуючих систем, телекомунікаційне середовище яких є мультисервісним, передбачає численні модифікації швидкої комутації пакетів, широкосмугову пакетну комутацію [1].

Постановка проблеми в загальному вигляді. В сучасних мультисервісних мережах необхідно проведення попередньої оцінки рівня вимог до основних параметрів мережі, в першу чергу до продуктивності центрів комутації і необхідної швидкості передачі цифрових трактів зв'язку, що дозволяе встановити відповідність між попитом, ємністю і пропускною спроможністю і дає відповідь на питання про можливість надання того чи іншого виду послуг. Однак розв'язанню цієї проблеми перешкоджає велика кількість факторів, таких як слаба вивченість телекомунікаційних мереж з інтегральним трафіком, відсутність загальних методик розрахунку характеристик трафіка в таких мережах і ін.

Аналіз останніх досліджень і публікацій. В [2] показано, що широкий діапазон швидкостей передачі, істотний статистичний характер інформаційних потоків в інтегральних мережах, велика різноманітність мережних конфігурацій значно ускладнюють опис трафіка в сучасних інформаційних системах в порівнянні з класичними мережами зв'язку.
В [3] обгрунтовано вимогу наявності можливості будь-якої зміни ширини смуги пропускання каналу, причому плавно і практично на будь-яку величину, що робить в ряді випадків неприйнятним для аналізу характеристик реального мережного трафіка використання класичного підходу [3], заснованого на марківських або напівмарківських моделях і припущеннях щодо пуассонівського характеру потоків [13]. У ряді робіт аналіз характеристик трафіка проводиться на основі його статистичного характеру в системах з довготривало залежними процесами на вході [4-12]. Однак, в загальному вигляді проблема оперативного отримання характеристик реального трафіка в мультисервісних мережах на сьогодні не вирішена [13, 14]. Зокрема, актуальною $є$ задача отримання оперативної оцінки статистичних характеристик трафіка, утвореного на комутаційних вузлах мережі при агрегуванні окремих інформаційних потоків, які направляються одним маршрутом.

Метою даної статті $\epsilon$ розробка методу, який дозволяє отримати оперативну оцінку основних статистичних характеристик агрегованого трафіка на комутаційному вузлі мультисервісної мережі, що здійснює статистичне мультиплексування вхідних потоків, використовуючи значення відліків вхідних потоків.

\section{Результати досліджень}

Розглянемо комутаційний вузол мультисервісної мережі, на якому для подальшого проходження мережею агрегується $I$ вхідних потоків (ВП) [3]. Нехай $i$-й потік $(i=\overline{1, I})$ характеризується випадковим процесом $V_{i}(t)$, що визначає сімейство випадкових функцій швидкості передачі інформації конкретних сеансів. Даний стохастичний процес, розглянутий протягом деякого часового інтервалу $\left[0, T_{i}\right]$, 
можна охарактеризувати такими параметрами [4]:

$$
V_{i}^{(\max )}=\max _{t \in\left[0, T_{i}\right]} V_{i}(t)-\text { піковою швидкістю пе- }
$$

редачі $i$-го ВП;

$$
V_{i}^{(c p)}=\int_{0}^{T_{i}} V_{i}(t) d t-\text { середньою швидкістю пе- }
$$

редачі (математичним сподіванням) і-го ВП;

$$
k_{i}^{(p)}=\frac{V_{i}^{(\max )}}{V_{i}^{(c p)}}-\text { берстністю [3], що визначає }
$$

співвідношення між величинами пікової та середньої швидкості;

$$
T_{i}^{(\max )}-\text { тривалістю пікового навантаження. }
$$

Нехай обсяг інформації, переданої за час $t \in\left[0, T_{i}\right]$, характеризується випадковою величиною $W_{i}(t)$ з максимально можливим значенням

$$
W_{i}^{(\max )}=V_{i}^{(\max )} \cdot T_{i}^{(\max )} .
$$

Тоді

$$
V_{i}(t)=\frac{d W_{i}(t)}{d t}
$$

Розглянемо ймовірність досягнення пікової швидкості передачі трафіка і-го ВП на даному часовому інтервалі $\left[0, T_{i}\right]$, що дорівнює

$$
p_{i}=P\left(V_{i}(t)=V_{i}^{(\max )}\right) \text {. }
$$

Iз (1) и (3) випливає, що розглянута ймовірність характеризує не тільки швидкість передачі інформації, але і передані обсяги:

$$
\begin{gathered}
V_{i}(t)=V_{i}^{(\max )} \Rightarrow\left(V_{i}(t) \cdot T_{i}^{(\max )}=V_{i}^{(\max )} \cdot T_{i}^{(\max )}\right) \equiv \\
\equiv\left(W_{i}(t)=W_{i}^{(\max )}\right) \Rightarrow P_{i}=P\left(W_{i}(t)=W_{i}^{(\max )}\right) .
\end{gathered}
$$

Розіб'ємо часовий інтервал $\left[0, T_{i}\right]$ на дві підмножини вкладених інтервалів таким чином:

$$
\begin{gathered}
\mathfrak{J}_{i}^{(1)} \cup \mathfrak{J}_{i}^{(2)}=\left[0, T_{i}\right] ; \mathfrak{J}_{i}^{(1)} \cap \mathfrak{J}_{i}^{(2)}=\varnothing ; \\
\forall t^{(1)} \in\left[t_{i}^{(1)} ; t_{i}^{\prime(1)}\right] \subset \mathfrak{J}_{i}^{(1)} \Rightarrow V_{i}\left(t^{(1)}\right)=V_{i}^{(\max )} ; \\
\forall t^{(2)} \in\left[t_{i}^{(2)} ; t_{i}^{\prime(2)}\right] \subset \mathfrak{J}_{i}^{(2)} \Rightarrow V_{i}\left(t^{(2)}\right)<V_{i}^{(\max )} .
\end{gathered}
$$

Розбиття (4) дозволяє визначити тривалість пікового навантаження на заданому інтервалі

$$
T_{i}^{(\max )}=\sum_{\left[t_{i}^{\prime(1)} ; t_{i}^{\prime \prime(1)}\right] \subset \Im_{i}^{(1)}}\left|t_{i}^{\prime(1)}-t_{i}^{(1)}\right|
$$

i знайти значення ймовірності досягнення пікової швидкості передачі трафіка $i$-го ВП на розглядаємому часовому інтервалі. Для цього розрахуємо площі, що відповідають $\mathfrak{J}_{i}^{(1)}$ и $\mathfrak{J}_{i}^{(2)}$ :

$$
\begin{gathered}
\Theta_{1}=\int_{\Im_{i}^{(1)}} V_{i}(t) d t=V_{i}^{(\max )} \cdot T_{i}^{(\max )} ; \\
\Theta_{2}=\int_{\Im_{i}^{(2)}} V_{i}(t) d t ; \\
\Theta=\Theta_{1}+\Theta_{2}=V_{i}^{(\max )} \cdot T_{i}^{(\max )}+\Theta_{2} .
\end{gathered}
$$

Тоді шукана ймовірність дорівнює

$$
p_{i}=\frac{\Theta_{1}}{\Theta}=\frac{V_{i}^{(\max )} \cdot T_{i}^{(\max )}}{V_{i}^{(\max )} \cdot T_{i}^{(\max )}+\Theta_{2}} .
$$

Використовуючи узагальнену інтегральну теорему про середнє запишемо, що

$$
\exists \eta \in\left[0, T_{i}\right] \quad \Theta_{2}=V_{i}(\eta) \cdot\left(T_{i}-T_{i}^{(\max )}\right) .
$$

Вважаючи, що

$$
\Theta=\Theta_{1}+\Theta_{2}=V_{i}^{(c p)} \cdot T_{i},
$$

а також вираз (7), знайдемо значення $\Theta_{2}$ :

$$
\Theta_{2}=\Theta_{2}=V_{i}^{(c p)} \cdot T_{i}-V_{i}^{(\max )} \cdot T_{i}^{(\max )} .
$$

Відмітимо, що із (10) и (12) випливає, що

$$
V_{i}(\eta)=\frac{\Theta_{2}}{T_{i}-T_{i}^{(\max )}}=\frac{V_{i}^{(c p)} \cdot T_{i}-V_{i}^{(\max )} \cdot T_{i}^{(\max )}}{T_{i}-T_{i}^{(\max )}} .
$$

Із (9) и (11) отримаємо, що

$$
p_{i}=\frac{V_{i}^{(\max )} \cdot T_{i}^{(\max )}}{V_{i}^{(c p)} \cdot T_{i}}=k_{i}^{(p)} \cdot \frac{T_{i}^{(\max )}}{T_{i}} .
$$

Вважаючи на те, що розглядається трафік окремого джерела, $\Theta_{2}>0$ [3], тобто, виходячи із (12) отримаємо:

$$
\begin{gathered}
V_{i}^{(c p)} \cdot T_{i}-V_{i}^{(\max )} \cdot T_{i}^{(\max )}>0 ; \\
\frac{V_{i}^{(\max )}}{V_{i}^{(c p)}} \cdot \frac{T_{i}^{(\max )}}{T_{i}}<1 \Rightarrow k_{i}^{(p)} \cdot \frac{T_{i}^{(\max )}}{T_{i}}<1,
\end{gathered}
$$

що узгоджується з виразом (13).

Знаючи ймовірність досягнення пікової швидкості можна визначити ймовірність того, що пікова швидкість не буде досягнута:

$$
q_{i}=1-p_{i}=P\left(V_{i}(t)<V_{i}^{(\max )}\right) .
$$


Для подальшого аналізу необхідно знати величину розкиду можливих значень випадкової величини $V_{i}$ на даному часовому інтервалі $\left[0, T_{i}\right]$.

Для цього визначимо щільність розподілу $f\left(V_{i}\right)$ даної випадкової величини, при якій досягається $\sup D\left[V_{i}\right]$.

При відомої щільності ймовірності дисперсія розраховується як

$$
\begin{aligned}
& D\left[V_{i}\right]=\int_{-\infty}^{\infty} V_{i}^{2} f\left(V_{i}\right) d V_{i}-M^{2}\left[V_{i}\right]= \\
& =\int_{0}^{V_{i}} V_{i}^{2} f\left(V_{i}\right) d V_{i}-\left(\int_{0}^{V_{i}} V_{i} f\left(V_{i}\right) d V_{i}\right)^{2} .
\end{aligned}
$$

Аргумент $V_{i}$ приймає значення у діапазоні від $V_{i}^{(\min )}$ до $V_{i}^{(\max )}\left(0 \leq V_{i}^{(\min )}<V_{i}^{(\max )}\right)$. Виходячи із цього проведемо апроксимацію $D\left[V_{i}\right]$, розбивши відрізок $\Delta=\left[V_{i}^{(\min )} ; V_{i}^{(\max )}\right]$ на $\mathrm{n}$ рівних частин $\Delta_{j}=\left[V_{i}^{(j-1)} ; V_{i}^{(j)}\right]$ таким чином, що:

$$
\bigcup_{j=1}^{n} \Delta_{j}=\Delta ; \bigcap_{j=1}^{n} \Delta_{j}=\varnothing
$$

Тоді вибравши всередині кожного відрізка $\Delta_{j}$ за теоремою про інтегральне середнє точку $\xi_{\mathrm{j}}$, дисперсію можна представити, виходячи із (11), як

$$
\begin{gathered}
D\left[V_{i}\right]= \\
=\sum_{o=1}^{m} \xi_{j}^{2} \cdot \int_{V_{i}^{j-1}}^{V_{i}^{j}} f\left(V_{i}\right) d V_{i}-\left(\sum_{o=1}^{m} \xi_{j} \int_{V_{i}^{j-1}}^{V_{i}^{j}} f\left(V_{i}\right) d V_{i}\right)^{2} \text { (16) } \\
\text { Відмітимо, що } \int_{V_{i}^{j-1}}^{V_{i}^{j}} f\left(V_{i}\right) d V_{i}=p_{j}, \quad \sum_{j=1}^{n} p_{j}=1,
\end{gathered}
$$

та позначивши $\vec{p}=\left(p_{1}, \ldots p_{n}\right)$. знайдемо екстремум дисперсії (16), використовуючи метод множників Лагранжа для задачі оптимізації:

$$
\begin{gathered}
\sum_{j=1}^{n} p_{j} \cdot \xi_{j}^{2}-\left(\sum_{o=1}^{n} p_{j} \cdot \xi_{j}\right)^{2} \rightarrow \text { extr } \\
\sum_{j=1}^{n} p_{j}=1, p_{j} \geq 0
\end{gathered}
$$

Складемо лагранжіан задачі (17):

$L(\vec{p}, \lambda)=\sum_{j=1}^{n} p_{j} \cdot \xi_{j}^{2}-\left(\sum_{o=1}^{n} p_{j} \cdot \xi_{j}\right)^{2}-\lambda\left(\sum_{j=1}^{n} p_{j}-1\right)$ та знайдемо його безумовний екстремум із такої системи рівнянь:

$$
\left\{\begin{array} { l } 
{ \frac { \partial L } { \partial p _ { j } } = 0 , j = \overline { 1 , n } ; } \\
{ \frac { \partial L } { \partial \lambda } = 0 }
\end{array} \Rightarrow \left\{\begin{array}{l}
\xi_{j}^{2}-2 \xi_{j}\left(\sum_{j=1}^{n} p_{j} \cdot \xi_{j}\right)-\lambda=0 \\
\sum_{j=1}^{n} p_{j}-1=0 .
\end{array}\right.\right.
$$

Из першого рівняння системи знайдемо $\xi_{j}$ :

$$
\xi_{j}=\tilde{m}_{\xi} \pm \sqrt{\tilde{m}_{\xi}^{2}+\lambda}, \text { где } \tilde{m}_{\xi}=\sum_{j=1}^{n} p_{j} \cdot \xi_{j},
$$

тобто для множників Лагранжа, що задовольняють умові $\lambda>-\tilde{m}_{\xi}^{2}$ існує тільки два різних значення $\xi_{j}$ : $\xi_{1}$ и $\xi_{2}$, при цьому:

$$
n=2 ; p_{1}=p_{i} ; p_{2}=1-p_{1}=q_{i},
$$

тобто функція розподілу ймовірності має дискретний вигляд, а щільність розподілу

$$
f\left(V_{i}\right)=p_{i} \delta\left(V_{i}-\xi_{1}\right)+q_{i}\left(V_{i}-\xi_{2}\right),
$$

де $\delta(\cdot)$ - функція Дірака.

Тоді для випадкової величини $V_{i}$ :

$$
\begin{gathered}
M\left[V_{i}\right]=p_{i} \xi_{1}+q_{i} \xi_{2}=p_{i} \xi_{1}+\left(1-p_{i}\right) \xi_{2} ; \\
D\left[V_{i}\right]=\left(1-p_{i}\right) p_{i}\left(\xi_{1}-\xi_{2}\right)^{2} .
\end{gathered}
$$

Вочевидь, що $\sup D\left[V_{i}\right]$ досягається при максимальному значенні множника $\left(\xi_{1}-\xi_{2}\right)^{2}$, тобто

$$
\xi_{1}=V_{i}^{(\max )} ; \quad \xi_{2}=V_{i}^{(\min )} .
$$

Із (21) - (23) слідкує, що

$$
M\left[V_{i}\right]=p_{i} V_{i}^{(\max )}+\left(1-p_{i}\right) V_{i}^{(\min )} .
$$

Але $M\left[V_{i}\right]=V_{i}^{(c p)}$, а значення $V_{i}^{(\min )}$ для реальних процесів можна прирівняти до нуля, тобто:

$$
\begin{aligned}
& p_{i}=V_{i}^{(c p)} / V_{i}^{(\max )}=\left(k_{i}^{(p)}\right)^{-1} ; \\
& D\left[V_{i}\right]=\left(1-p_{i}\right) p_{i}\left(V_{i}^{(\max )}\right)^{2} .
\end{aligned}
$$

3 огляду на те, що ВП, що надходять на комутаційний вузол, незалежні, виходячи з виразів (25) (27) розрахуємо математичне сподівання і дисперсію агрегованого потоку:

$$
M_{a}=\sum_{i=0}^{I} \frac{V_{i}^{(\max )}}{k_{i}^{(p)}}, \quad D_{a}=\sum_{i=0}^{I} \frac{1-k_{i}^{(p)}}{\left(k_{i}^{(p)}\right)^{2}}\left(V_{i}^{(\max )}\right)^{2} .
$$


Значення змінних $V_{i}^{(\max )}$ и $k_{i}^{(p)}$ можна отримати за відліками ВП на комутаційному вузлі значень випадкової величини $V_{i}$.

\section{Висновки та перспективи подальших досліджень}

У статті розглянуто метод, що дозволяє отримати оперативну оцінку основних статистичних характеристик (на прикладі математичного сподівання і дисперсії) агрегованого трафіку на комутаційному вузлі мультисервісної мережі, що здійснює статистичне мультиплексування вхідних потоків. Запропонований метод грунтується на апроксимації функції щільності розподілу швидкості окремого вхідного потоку трафіку. Доведено, що для отримання оцінки досить значень максимальної бітової швидкості і берстності кожного вхідного потоку, які розраховуються за відліком трафіку. Точність і часові витрати на розрахунок оцінки визначаються масштабом шкали відліків комутаційного вузла. Великомасштабні шкали підвищують оперативність розрахунку значень статистичних характеристик, однак дають істотну погрішність оцінки, дрібномасштабні шкали збільшують витрати обчислювального ресурсу комутаційного вузла, однак, знижують помилку репрезентативності. Тому завдання вибору оптимальної шкали відліків трафіку, що надходить на комутаційний вузол мультисервісної мережі, є напрямком подальших досліджень.

\section{СПИСОК ЛІТЕРАТУРИ}

1. Куроуз, Дж. Компьютерные сети. 2-е изд [Текст] / Дж. Куроуз, К. Росс. - СПб.: Питер, 2004. - 765 с.

2. Крылов В.В., Самохвалова С.С. Теория телетрафика и ее приложения. СПб.: БХВ-Петербург, 2005. 288 с.

3. Кучук, Г.А., Гахов, Р.П., Пашнев А.А. Управление ресурсами инфотелекоммуникаций. М.: Физматлит, 2006.220 с.

4. Кучук, Г.А. Моделювання трафіка мультисервісної розподіленої телекомунікаційної мережі [Текст] / Г.А. Кучук, І.Г. Кіріллов, А.А. Пашнєв // Системи обробки інформації. - Х.: ХУ ПС, 2006. - Вип. 9 (58). - С. 50 - 59.

5. Кучук Н.Г., Гавриленко С.Ю., Лукова-Чуйко Н.В., Собчук В.В. Перерозподіл інформаційних потоків у гіперконвенгертній системі / С.Ю. Гавриленко. Сучасні інформаційні системи. 2019. Т. 3, № 2. С. 116-121. DOI: https://doi.org/10.20998/2522-9052.2019.2.20

6. Nechausov A., Mamusuĉ I., Kuchuk N. Synthesis of the air pollution level control system on the basis of hyperconvergent infrastructures. Сучасні інформачійні системи. 2017. T. 1, № 2. C. 21-26. DOI: https://doi.org/10.20998/2522-9052.2017.2.04

7. Mozhaiev M., Kuchuk N., Usatenko M. (2019) The method of jitter determining in the telecommunication network of a computer system on a special software platform. Innovative technologies and scientific solutions for industries, 2019. Vol. 4 (10), pp. 134-140. doi: https://doi.org/10.30837/2522-9818.2019.10.134

8. Зиков I. С., Кучук Н. Г., Шматков С. І. Синтез архітектури комп'ютерної системи управління транзакціями еlearning. Сучасні інформаційні системи. 2018. Т. 2, № 3. C. 60-66. DOI: https://doi.org/10.20998/2522-9052.2018.3.10

9. Гахов Р.П. Моделирование трафика беспроводной сети передачи данных / Р. П. Гахов, Н. Г. Кучук// Научные ведомости БелГУ. - 2014. - № 1 (172). - Вып. 29(1). - С. 175-181.

10. Коваленко А. А., Кучук Г. А. Методи синтезу інформаційної та технічної структур системи управління об'єктом критичного застосування. Сучасні інформаційні системи. 2018. Т. 2, № 1. С. 22-27. DOI: https://doi.org/10.20998/2522-9052.2018.1.04

11. Свиридов А. С., Коваленко А. А., Кучук Г. А. Метод перерозподілу пропускної здатності критичної ділянки мережі на основі удосконалення ON/OFF-моделі трафіку. Сучасні інформаційні системи. 2018. Т. 2 , № 2. C. 139-144. DOI: https://doi.org/10.20998/2522-9052.2018.2.24

12. Кучук Н. Г. Метод зменшення часу доступу до слабкоструктурованих даних / Н. Г. Кучук, В. Ю. Мерлак, В. В. Скородєлов // Сучасні інформачійні системи = Advanced Information Systems. - 2020. - T. 4, № 1. - C. 97-102. doi: https://doi.org/10.20998/2522-9052.2020.1.14

13. Кучук, Г.А. Розрахунок навантаження мультисервісної мережі [Текст] / Г.А. Кучук, Я.Ю. Стасєва, О.О. Болюбаш // Системи озброєння і військова техніка. - 2006. - № 4 (8). - С. 130 - 134.

14. Олифер, В.Г. Компьютерные сети. Принципы, технологии, протоколы [Текст] / В.Г. Олифер, Н.А. Олифер. - СПб.: Питер, 2012. - 943 c

Received (Надійшла) 16.09.2020

Accepted for publication (Прийнята до друку) 28.10.2020

\section{Method of the aggregated traffic statistical descriptions operative estimation}

I. Liberg, O. Mozhayev, H. Kuchuk

Abstract. The purpose of the article is to develop a method that allows to obtain an operational assessment of the main statistical characteristics of aggregated traffic at the switching node of a multiservice network, which performs statistical multiplexing of input streams using the values of input streams. Results. A method is proposed that allows to obtain an operative estimate of the main statistical characteristics (on the example of mathematical expectation and variance) of aggregated traffic at the switching node of the multiservice network, which performs statistical multiplexing of input streams. The proposed method is based on the approximation of the density distribution function of a single input traffic flow. It is proved that the values of the maximum bit rate and roughness of each input stream, which are calculated from the traffic count, are sufficient to obtain an estimate. The accuracy and time spent on calculating the estimate are determined by the scale of the scale of the switching node. Large-scale scales increase the efficiency of calculating the values of statistical characteristics, but give a significant error of estimation, small-scale scales increase the cost of the computing resource of the switching node, however, reduce the error of representativeness.

Keyword s: aggregated traffic, multiservice network, interconnect knot, berst, function of distributing closeness, bit flowrate. 